\title{
Non-medical Remedies and Medication Adherence: A Neglected Aspect of Healthcare Delivery
}

\section{Tony Cassidy*}

University of Ulster, Psychology Coleraine, UK

*Corresponding author: Tony Cassidy, University of Ulster, Psychology Coleraine, UK, Tel: 44028 70123025; E-mail: t.cassidy@ulster.ac.uk

Rec date: Oct 20, 2015, Acc date: Dec 16, 2015, Pub date: Dec 24, 2015

Copyright: (c) 2015 Cassidy T. This is an open-access article distributed under the terms of the Creative Commons Attribution License, which permits unrestricted use, distribution, and reproduction in any medium, provided the original author and source are credited.

\begin{abstract}
Background: Belief in non-medical remedies such as 'folk' cures and faith healing are likely to impact on patients' relationship with health care, and one area of particular current interest is adherence to medication.

Aim: The aim was to explore the impact of such beliefs and patients' satisfaction with healthcare on self-reported adherence to medication.
\end{abstract}

Method: A survey using questionnaire measures assessed 766 participants (326 males and 440 females) ranging in age from 18-69 years.

Results: Results showed that self-reported adherence was significantly correlated with satisfaction with medical interviews but when the individual dimensions of satisfaction were explored it was distress relief and rapport rather than communication that accounted for the variance. Intention to use non-medical treatments was correlated with self-reported non-adherence and was the single significant predictor from multiple regression analysis.

Conclusions: It was concluded that cultural beliefs related to non-medical treatments are intricately linked to patients' interaction with health care. The existence of such beliefs needs to be fully integrated into an analysis of health and illness behaviours, particularly in regard to adherence to medication.

Keywords: Adherence; Satisfaction; Non-medical treatment.

\section{Introduction}

Adherence to medication is "the extent to which a patient's behavior coincides with medical or prescribed health advice" [1]. Many patients (30-50\%) do not adhere to the medical regime specified by their doctor [2], who costs the patient in terms of quality of life, and health services vast amounts of precious funds [3]. In the UK the cost to the NHS is estimated around $£ 300$ million [2] and the US between $\$ 100$ billion and $\$ 289$ billion annually $[4,5]$. Intervention strategies are essential if patients are to reap the benefits of modern medical therapies and while there has been some real success [6], many are ineffective suggesting there is still work to be done [7].

A wide range of factors contributing to poor medication adherence have been identified, including patient-related factors (e.g., health literacy and lack of decision-making participation), physician-related factors (e.g., complexity of medical regimens, patient-doctor communication, and changes in physicians), and health care systemsrelated factors (e.g., .time limitations, access to care, and poor health information technology) $[8,9,4]$.One set of factors that get no mention in this list are cultural / religious beliefs, and when they are mentioned it is in terms of non-Western cultures [10]. Yet in Western society we still have a range of cultural beliefs in 'folk' cures and spiritual healing which may conflict with medical regimen [11].

A folk cure is any purported health remedy which is based on a prescientific tradition usually handed down from generation to generation through oral history. Some folk remedies have made their way into alternative medicines and even into mainstream medical potions. They are not generally part of a medical regimen and anecdotal evidence would suggest that they may conflict with, or at least reduce trust in, medical advice. The other form of non-medical remedy prevalent in many societies is the belief in, or practice of, faith healing. This study has nothing to say about the efficacy of non-medical remedies its thesis is simply that belief in such remedies may interfere with patient's adherence to medical regimen.

Theoretically, a link between non-medical remedies and adherence to medical regimes can easily be postulated. Leventhal's selfregulatory / common sense model of illness representations proposes that a patient's adherence to medication is largely influenced by their illness representation $[12,13]$. Central to illness representations are the beliefs the individual holds about the causes, consequences and potential cures for their illness. This model has been extensively used to explain and to design interventions to improve adherence [12].

The other well established model to explain patient adherence is the cognitive model proposed by [14] in which adherence is seen as a direct effect of patient satisfaction which is in turn influenced by doctor-patient communication [15]. Patient satisfaction (contributed to by memory and understanding), particularly patient satisfaction with health professionals is an important predictor of adherence $[16,17]$. Thus, the health sector emphasises developing their professionals communication skills, to facilitate patient understanding and memory through patient centered care/shared decision making $[14,18]$. However, adherence is an interaction, and thus an 
Page 2 of 5

understanding of the position of the patient is also essential if health professionals are to facilitate patients integrating the new information into their existing schemas.

Patients are unlikely to disclose their belief in non-medical remedies, in the same way as most patients do not disclose the use of Complementary and Alternative Medicine (CAM) in general to their physician [19]. On the other hand many doctors do not check how satisfied their patients are with the medical consultation. Evidence has shown that those individuals who have a strong belief in the efficacy of CAMs before any diagnosis is made for them, also tend to use such treatments in response to any illness they experience [20].

Overall, based on the theoretical models proposed to explain adherence, the current study aims to test the suggestions that belief in non-medical remedies may be related to lower self-reported adherence behaviour, and lower satisfaction with medical interviews, and that satisfaction with medical interviews may be a mediator or moderator of the relationship between belief in non-medical remedies and adherence.

\section{Method}

\section{Design}

The study used a cross sectional survey design with questionnaire data collection to explore the relationship between belief in and intention to use non-medical remedies, reported satisfaction with GP interviews, and reported adherence to medical regimen.

\section{Participants}

These were 766 adults, 326 males and 440 females, ranging in age from 18-69 years and with a mean age of 30.4. Of these 211 were currently on medication with 159 on long term treatment.

\section{Materials}

As well as demographic questions about age, sex and current medication, participants were assessed on the following measures.

The Medical Interview Satisfaction Scale (MISS-21) [21] which is a 21 item British version of the original scale devised by [22]. It measures 4 factors, Distress Relief, Communication Comfort, Rapport, and Compliance Intent. The scale has an overall Cronbach alpha of .92. Individual factor alphas range from .77 to .90 .

The Belief in and Intention to use Non-medical Remedies (BINR). This is a newly developed 5 item measure of beliefs and intentions in regard to traditional cures and faith healing remedies. The scale has a Cronbach Alpha of .80. A sample item is 'I would go to a faith healer for treatment?.

An Adherence scale developed for the current study as described in the results section. This was an 8 item scale with a Cronbach Alpha of 97. The items are outlined in Table 1.

\section{Procedure}

Participants were accessed via a 'family' snowball sampling technique in which an initial sample of 150 psychology students were asked to complete a questionnaire and recruit up to 5 members of their family aged 18 or over to participate in the study. The aim was to access a mix of age groups. Of the target of 900,766 usable questionnaires were returned for analysis.

\section{Results}

The aim of the current study was to explore the relationship between belief in and intention to use non-medical remedies, reported satisfaction with GP interviews, and reported adherence to medical regimen. The first stage of this involved the development of a measure of adherence.

\section{The adherence scale}

A pool of 8 items was constructed and administered to the study sample as part of the overall set of measures. Using Principal Component Analysis with Varimax rotation a single factor was produced accounting for $77.4 \%$ of the variance. All 8 items loaded on this factor. A Reliability Analysis produced a Cronbach's Alpha of .96 for this 8 item scale see Table 1 .

\begin{tabular}{|l|l|l|}
\hline \multicolumn{2}{|l|}{ Cronbach Alpha $=.97$} & \multirow{2}{*}{ Factor Loadings } \\
\hline \multirow{2}{*}{} & Items & \\
\hline 1. & I always take my medicine or tablets & 0.922 \\
\hline 2. & I sometimes miss my medicine or tablets by accident & 0.855 \\
\hline 3. & I sometimes decide not to take my medicine or tablets & 0.922 \\
\hline 4. & I take some of my medicine or tablets but not all of it & 0.928 \\
\hline 5. & I always follow my doctor's advice & 0.936 \\
\hline 6. & I sometimes ignore what my doctor tells me & 0.924 \\
\hline 7. & I attend my doctor regularly & 0.832 \\
\hline 8. & I have to be forced to go to my doctor & 0.689 \\
\hline
\end{tabular}

Table 1: Items, factor loadings, and reliability statistics for the Adherence Scale.

The next stage in analysis was to explore the relationship between adherence (as measured by the new scale), belief in and intention to use non-medical remedies (as measured by the BINR), and the 4 factors of the MISS, distress relief, communication, rapport, and compliance intent, using Pearson correlations see Table 2.

\begin{tabular}{|l|l|l|l|l|l|r|r|r|r|}
\hline & & & & 2 & 3 & 4 & 5 & 6 & 7 \\
\hline 1. Adherence & & & $-.69^{* * *}$ & $.44^{* * *}$ & $.17^{* *}$ & $.44^{* * *}$ & $.20^{* *}$ & $.45^{* * *}$ & \\
\hline 2. Belief in non-n & $-.39^{* * *}$ & 0.03 & $-.32^{* * *}$ & -0.06 & $-.31^{* * *}$ & & & & \\
\hline 3. Distress relief & & & & $.30^{* * *}$ & $.67^{* * *}$ & $.36^{* * *}$ & $.82^{* * *}$ & \\
\hline 4. Communication & & & & & $.46^{* * *}$ & $.57^{* * *}$ & $.67^{* * *}$ & \\
\hline 5. Rapport & & & & & & $.37^{* * *}$ & $.90^{* * *}$ & \\
\hline 6. Compliance intent & & & & & & $.62^{* * *}$ & & \\
\hline 7. MISS & & & & & & & & \\
\hline
\end{tabular}

Self-reported adherence was significantly negatively correlated with belief in non-medical remedies $(\mathrm{r}=-.69, \mathrm{p}<.001)$, and significantly positively with overall satisfaction with GP interviews $(r=.45, p<.001)$, as well as the satisfaction dimensions of distress relief $(\mathrm{r}=.44, \mathrm{p}<.001)$, communication $(\mathrm{r}=.17, \mathrm{p}<.01)$, compliance intent $(\mathrm{r}=.20, \mathrm{p}<.01)$, and rapport $(\mathrm{r}=.29, \mathrm{p}<.01)$ correlate significantly with adherence. The next stage in analysis used Hierarchical Multiple Regression Analysis 
(HMRA) to identify the relative strengths of the predictors of adherence, and to identify any mediating or moderating effects. Separate HMRAs were carried out the first with belief in non-medical remedies and the overall satisfaction score on the MISS as potential predictors of adherence, and the second with belief in non-medical remedies and the 4 dimensions of the MISS (distress relief, communication, rapport, and compliance intent), as potential predictors see Table 3 .

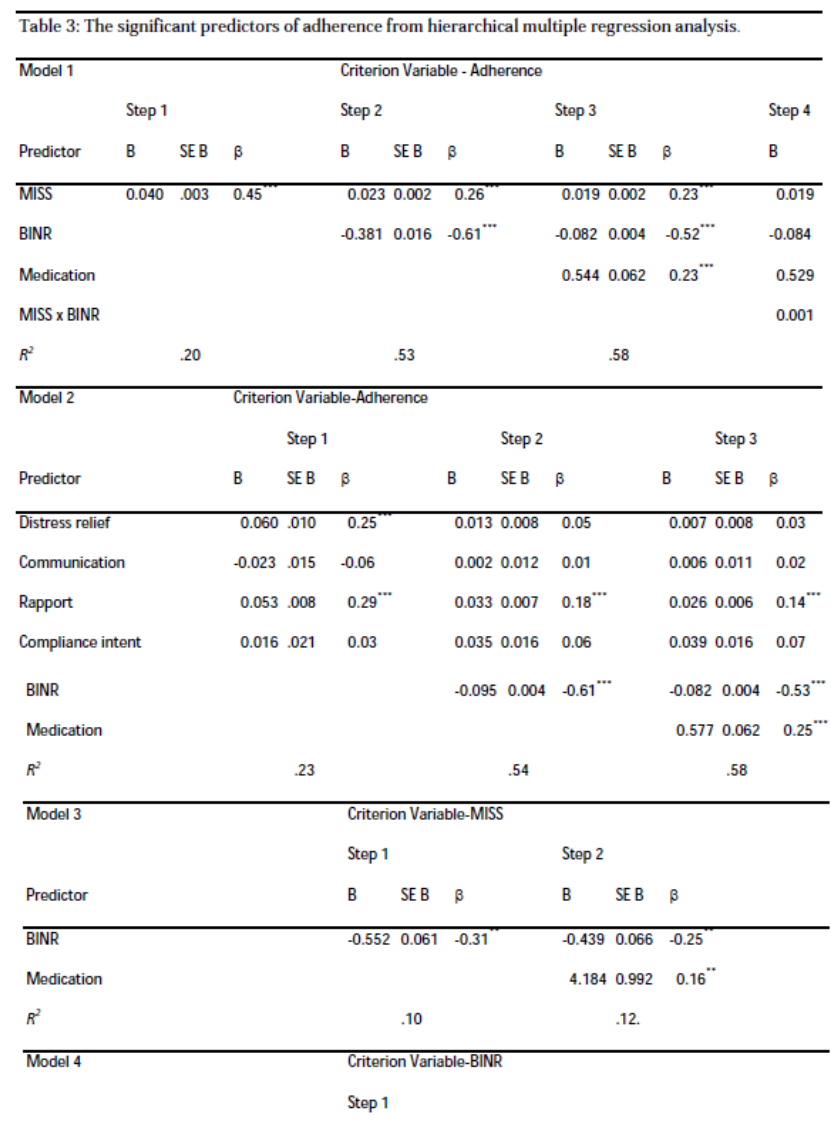

In both analyses belief in non-medical remedies was the largest single predictor adding over $30 \%$ to the amount of variance predicted. In model 1 satisfaction with GP interviews accounted for $20 \%$ of the variance in self-reported adherence and being on medication accounted for a further $5 \%$. To test if satisfaction might moderate the relationship between belief in non-medical remedies and adherence, an interaction variable was calculated from the product of belief in non-medical remedies and satisfaction and entered as a potential predictor. Both variables were centred before calculation to try to reduce multicolliniarity. The interaction variable is added in step 4 of model 1 and although it is significant at the .05 level it adds less than $1 \%$ of the explained variance.

In order to test if satisfaction with GP interviews might mediate the relationship between belief in non-medical remedies and adherence, the overall MISS score was used as a dependent or criterion variable in a separate HMRA. Belief in non-medical remedies did emerge as a significant predictor accounting for $10 \%$ of the variance therefore the requirement for mediation was met see Figure 1.

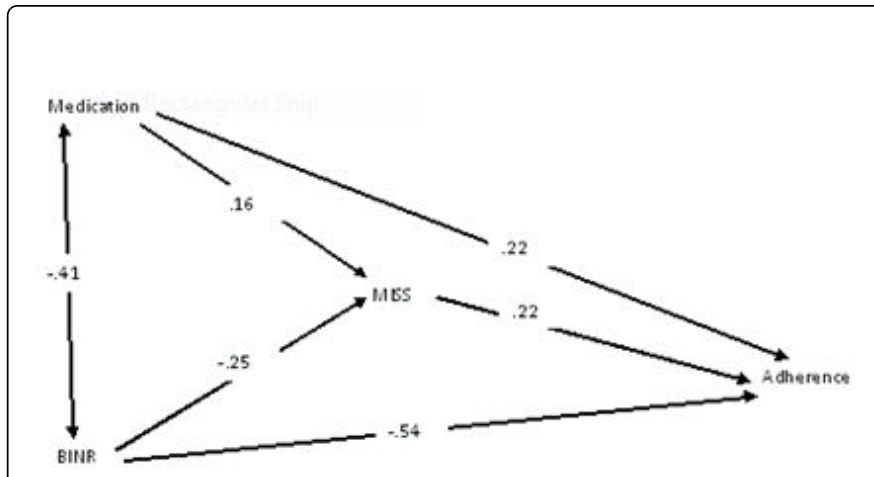

Figure 1: A meditational model of adherence from HMRA using beta values.

In the sample 370 were currently on medication with 159 of these on long term treatment, and 396 not currently on any form of medication. A one-way Anova was used to test for differences between these medication groups on adherence, belief in non-medical remedies, and satisfaction. Means and standard deviations are shown in Table 4.

\begin{tabular}{|l|l|l|l|}
\hline & $\begin{array}{l}\text { Not on } \\
\text { medication } \\
(\mathrm{N}=396)\end{array}$ & $\begin{array}{l}\text { On short term } \\
\text { medication (N=211) }\end{array}$ & $\begin{array}{l}\text { On long term } \\
\text { medication } \\
(\mathrm{N}=159)\end{array}$ \\
\hline Mean (Sd) & Mean (Sd) & Mean ( Sd) \\
\hline Adherence & $4.37(1.01)$ & $5.62(0.99)$ & $5.47(1.11)$ \\
\hline MISS & $67.8(13.6)$ & $74.7(12.8)$ & $74.6(11.3)$ \\
\hline Distress relief & $18.4(4.5)$ & $21.7(5.3)$ & $20.8(4.2)$ \\
\hline Communication & $14.2(3.5)$ & $14.4(3.1)$ & $14.2(2.5)$ \\
\hline Rapport & $24.7(6.7)$ & $28.3(5.7)$ & $28.6(5.1)$ \\
\hline Compliance intent & $10.5(2.3)$ & $10.5(2.2)$ & $10.9(2.0)$ \\
\hline BINR & $4.96(1.68)$ & $3.26(1.69)$ & $3.65(1.83)$ \\
\hline
\end{tabular}

Table 4: Means and standard deviations for the three medical categories.

There were significant main effects for adherence $(F(2,765)=128.9$, $\mathrm{p}<.001)$, overall satisfaction $(\mathrm{F}(2,765)=27.2, \mathrm{p}<.001)$, distress relief $(\mathrm{F}(2,765)=39.3, \mathrm{p}<.001)$, rapport $(\mathrm{F}(2,747)=8.42, \mathrm{p}<.001)$, and belief in non-medical remedies $(\mathrm{F}(2,765)=37.1, \mathrm{p}<.001)$. Those who are not on medication scored significantly lower on self-reported adherence than either those on short term, or those on long term medication. In terms of overall satisfaction with medical interviews those not on medication scored significantly lower than the other two groups. It appears that those on medication whether short or long term report both higher levels of adherence and higher levels of satisfaction with their GPs. This trend is replicated on the distress relief and rapport dimensions of the MISS with those on no medication reporting significantly lower levels than either of the other groups. The groups did not differ on communication comfort or compliance intent. On belief in and intention to use non-medical remedies the trend was reversed. Those on long term and those on short term medication scored significantly lower than those not on medications at all. 


\section{Discussion}

The aim of the current study was to explore the relationship between belief in non-medical remedies, reported satisfaction with GP interviews, and reported adherence to medical regimen, using a newly constructed measure. The adherence scale was shown to be unidimensional, and internally consistent. Results showed that adherence was significantly inversely correlated with belief in nonmedical remedies, and overall satisfaction with GP interviews, as well as the satisfaction dimensions of distress relief, communication, compliance intent, and rapport. However, belief in non-medical remedies was the largest independent predictor of non-adherence. Analyses indicated that this relationship was mediated by satisfaction with GP interviews. However while satisfaction with medical interviews was a mediator it did not moderate the impact of belief in non-medical remedies on adherence.

As predicted, stronger belief in non-medical remedies was associated with lower self-reported adherence to medications. The current results would support the suggestion that the belief in nontraditional remedies such as faith healers and cures has the potential to put health and even life at risk. Specifically, although existing research has well documented patient satisfaction with health professionals as an important predictor of adherence $[16,17]$,the current results outline that belief in non-traditional remedies may have even more potency as a predictor of adherence. This is important in that even though the mechanisms through which faith healing operates are poorly understood, and the prevalence and strength of belief in faith healing may vary and may not be as strong in the UK as in countries such as Pakistan, it has the potential to interfere with effective medical care. It is suggested that up to $75 \%$ of people in Ireland believe in the power of faith healers, though in our sample only $23 \%$ endorsed an unequivocal belief. A further $26 \%$ said they partially believed but just over $50 \%$ did not believe at all.

These findings can be aligned with Leventhal's self-regulatory/ common sense model of illness behavior, in that individuals' whose course of action to restore regulation in response to illness or threat of illness leads them to use faith healing, may be less likely to adhere to a strict biomedical regime, due to their positive appraisal of traditional cures. This is in accordance with the findings of Knuti et al. who found that faith and the use of faith healers is associated with reduced adherence to traditional biomedical regimes for illness. However, it must be acknowledged that the research of Reniers and Tesfai did not document any such association. Reasons for the discrepancy may be differences in the society examined (USA versus Ethiopia respectively), the use of a particular religious grouping (Jehovah's Witness) versus a community sample, or even the study methodology (qualitative versus quantitative). We did not examine religious belief in our study.

Overall, the current results are of applied importance in health professional's difficult task of designing interventions to improve patient's adherence [7]. Health care professionals need to examine patient's beliefs regarding faith healing as wells any other beliefs that may contradict trust in medicine and integrate this into an adherence plan. On belief in non-medical remedies those on long term and those on short term medication did not differ from each other but both scored significantly lower than those not on medications at all. This is some consolation since it appears that when in need of medication belief in faith healing may be challenged. Nonetheless, other factors are obviously at work in relation to the nature of the illness impacting upon adherence. Those on medication reported significantly higher self-reported adherence, satisfaction with medical interviews, distress relief and communication comfort and rapport compared with those on long term, or those not on, medication. The factors underlying this difference require further investigation, and integration into intervention strategies.

Our findings also showed that those with a strong belief in nontraditional remedies such as cure reported low satisfaction with medical interviews, supporting the findings of that patient whose spiritual needs are not met reported lower ratings of quality and satisfaction with care. Furthermore in support to our suggestion that this in turn may impact upon adherence, the relationship between belief in cures and adherence does appear to be mediated by patient satisfaction. The fact that the majority of physicians are skeptical of faith healing [24] does not appear to bear any major impact upon adherence. It would appear to be sufficient that although most primary care physicians do not initiate any involvement with patients' spirituality, they comply with incorporation if the patient asks for it [25].

Of course physicians are already busy and sometimes perhaps overloaded so that time to discuss issues such as belief in non-medical remedies with patients is difficult to find. However there is a potential role here for other health professionals such as health psychologists who can focus more on the issue of adherence [26], describe a trial in Italy where trained nurses undertook a care management role which linked physicians and patients in a strong partnership which improved care and empowered patients.

While the current results provide much interesting information for health professionals given that holistic treatment is increasing in popularity amongst lay people and health professionals alike, limitations do need to be acknowledged. Evidence has shown that those individuals who have a strong belief in the efficacy of CAMs before any diagnosis is made for them, also tend to use such treatments in response to any illness they experience [20]. However, evidence had not been obtained that this is also the case for faith healing. Given that the current results are based on a community sample in a variety of situations with regard to their health this would need examination.

Finally, although it must be acknowledged that the current results are based on self-report measures, questionnaires are considered concordant with other measures of medication adherence [27]. Overall, the current results provide a very useful starting point. Belief in non-medical remedies such as faith healing and cures appears to be an important predicator of non-adherence to medications. Future research must concentrate on further teasing out the dynamics of this relationship so that health professional can incorporate this into the patient centered care, and increase patient satisfaction and adherence.

\section{References}

1. Julius RJ, Novitsky MA Jr, Dubin WR (2009) Medication adherence: a review of the literature and implications for clinical practice. J Psychiatr Pract 15: 34-44.

2. Brown MT, Bussell JK (2011) Medication adherence: WHO cares? Mayo Clin Proc 86: 304-314.

3. Hovstadius B, Petersson G (2011) Non-adherence to drug therapy and drug acquisition costs in a national population--a patient-based register study. BMC Health Serv Res 11: 326.

4. Osterberg L, Blaschke T (2005) Adherence to medication. N Engl J Med 353: 487-497.

5. Peterson AM, Takiya L, Finley R (2003) Meta-analysis of trials of interventions to improve medication adherence. Am J Health Syst Pharm 60: 657-665. 
Citation: Cassidy T (2015) Non-medical Remedies and Medication Adherence: A Neglected Aspect of Healthcare Delivery. J Gen Practice 3:

Page 5 of 5

6. de Bruin M, Viechtbauer W, Hospers HJ, Schaalma HP, Kok G (2009) 'Standard care quality determines treatment outcomes in control groups of HAART-adherence intervention studies: Implications for the interpretation and comparison of intervention effects'. Health Psychology 28: 668-674

7. Haynes RB, Ackloo E, Sahota N, Mc Donald HP, Yao X (2008) Interventions for enhancing medication adherence. Cochrane Database of Systematic Reviews2, CD000011

8. Horne R, Weinman J, Barber N, Elliott R, Morgan M, et al. (2005) Concordance, adherence and compliance in medicine taking: conceptual map and research priorities. London: National Institute for Health Research (NIHR) Service Delivery and Organisation (SDO) Programme.

9. Jin J, Sklar GE, Min Sen Oh V, Chuen Li S (2008) Factors affecting therapeutic compliance: A review from the patient's perspective. Ther Clin Risk Manag 4: 269-286.

10. Chia LR, Schlenk EA, Dunbar-Jacob J (2006) Effect of personal and cultural beliefs on medication adherence in the elderly. Drugs Aging 23: 191-202.

11. MooreR Mc, Clean S (2010) Folk Healing and Health Care Practices in Britain and Ireland: Stethoscopes, Wands and Crystals. Berghahn Books, Oxford.

12. Hagger MS, Orbell S (2003) A Meta-Analytic Review of the CommonSense Model of Illness Representations, Psychology \& Health 18: 141-184.

13. Leventhal H, Cameron L (1987) Behavioral theories and the problem of compliance. Patient Education and Counseling 10: 117-138.

14. Ley P (1988) Communicating with Patients: Improving communication, satisfaction and compliance. London. Chapman and Hall.

15. Teutsch C (2003) Patient-doctor communication. Med Clin North Am 87: 1115-1145.

16. Gross R, Tabenkin H, Porath A, Heymann A, Greenstein, M (2003) The relationship between primary care physicians' adherence to guidelines for the treatment of diabetes and patient satisfaction: findings from a pilot study. Family Practice20: 563-569.
17. Wroth TH, Pathman DE (2006) Primary medication adherence in a rural population: the role of the patient-physician relationship and satisfaction with care. J Am Board Fam Med 19: 478-486.

18. Robinson JH, Callister LC, Berry JA, Dearing KA (2008) Patient-centered care and adherence: definitions and applications to improve outcomes. Journal of the American Academy of Nurse Practitioners 20: 600-607.

19. Thomas K, Coleman P (2004) Use of complementary or alternative medicine in a general population in Great Britain. Results from the National Omnibus survey. J Public Health (Oxf) 26: 152-157.

20. Corner J, Yardley J, Maher E J, Roffe L, Young T, et al, (2009) Patterns of complementary and alternative medicine use among patients undergoing cancer treatment. European Journal of Cancer Care 18: 271-279.

21. Meakin R, Weinman J (2002) The 'Medical Interview Satisfaction Scale' (MISS-21) adapted for British general practice. Fam Pract 19: 257-263.

22. Wolf M H, Putnam S M, James AJ, Stiles WB (1978) The Medical Interview treatment-clinical applications. Journal of the American Medical Association 288: 2880-2883

23. Astrow AB, Wexler A, Texeira K, He MK, Sulmasy DP (2007) Is failure to meet spiritual needs associated with cancer patients' perceptions of quality of care and their satisfaction with care? J Clin Oncol 25: 5753-5757.

24. King DE, Sobal J, Haggerty J 3rd, Dent M, Patton D (1992) Experiences and attitudes about faith healing among family physicians. J Fam Pract 35: 158-162.

25. Monroe MH, Bynum D, Susi B, Phifer N, Schultz L, et al. (2003) Primary care physician preferences regarding spiritual behavior in medical practice. Archives of Internal Medicine163: 2751-2756.

26. Garber MC, Nau DP, Erickson SR, Aikens JE, Lawrence JB (2004) The concordance of self-report with other measures of medication adherence: a summary of the literature. Med Care 42: 649-652.

27. Ciccone MM, Aquilino A, Cortese F, Scicchitano P, Sassara M, et al. (2010) Feasibility and effectiveness of a disease and care management model in the primary health care system for patients with heart failure and diabetes (Project Leonardo). Vasc Health Risk Manag 6: 297-305. 